The book is recommended, especially to reference libraries.

R. D. Passey

${ }^{1}$ Passey, R. D., Lancet, ii, 107 (1962).

'Wynder, E. L., Graham, E. A., and Croninger, A. B., Cancer Research, 13, 855 (1953).

a Day, T. D., Brit. J. Cancer, 21, 56 (1967).

\section{SURVIVAL OF THE BRAVEST}

\section{Electrophysiological Methods in Biological Research}

By J. Bures, M. Petran and Jozef Zachar. Third revised edition. Pp. 824. (Prague: Publishing House of the Czechoslovak Academy of Sciences; New York and London: Academic Press, 1967.) 261s. 6d.

A воок, designed for beginners in a field of science, which costs in the region of $£ 13$, deserves a long, hard look. It can be assumed that almost no student in Great Britain (or in Czechoslovakia either, from where the book originates) could really afford it, and that the publishers would have their eyes on the libraries of the universities and research institutions. Even so, the number of journals and books demanding the scrutiny of librarians and their committees is ever increasing, and budgets are tight. I approached the book, therefore, faintly irritated that the people it is specially written for are those least likely to lay their hands on it easily. Unfortunately, the more I read this book, the more my irritation increased.

About a third of the volume consists of conventional descriptions of basic electrical theory and details of circuits, and two appendices; one is of stereotaxic atlases for cat, rabbit and rat (can they improve on alreadyseparately-published ones ?), and one, entirely mathematical, does not match (in the space allotted) accounts in readily available textbooks. We are thus obliged to contribute some $£ 4$ for information which, when it is needed, can be easily obtained without the awful disadvantage, as here, of having simultaneously to deny one's colleagues access to another valuable and instructive book. That book ought to be extracted from the present volume; it provides almost everything that investigators of excitable structures ought to know about electrophysiological techniques, before, during, and after their experiments. It rightly forms the proper subject of this review.

It is clearly an important work. The main part deals with the electrophysiological investigations of excitable structures, in plants and animals, in vitro and in situ. These chapters, and those sections dealing with more general practical preparations for, and conduct during, experiments (electrode making, fault finding, artefacts, data-processing) and the basic principles of stimulating and recording, are very good indeed. Here are experiments ranging from the intracellular recording of action potentials, of miniature and end-plate potentials, of receptor potentials, to those investigating spreading depression in the cortex, or the production of stereotaxically controlled deep brain lesions. The principle of each experiment is made clear, and also the method-occasionally in impressive detail-and the conclusions from the results. It seems that every important experiment requiring electrophysiological techniques which has been performed since the War (and some even earlier) is here, with satisfactory references to the original work. The truly astonishing item is that all the included experiments were re-done by the authors, and the hints and suggestions are based on their own experience. Sometimes this is better than reading the original papers; one knows only too well the reluctance, or diffidence, of experimenters when it comes to describing the miseries and frustrations of the early trials which led to the polished technique actually incorporated into the "Methods". However, in this respect even this commendable book actually fails. It is as though, reluctant to reduce the full extent of their remarkable achievement in successfully reproducing so many original experiments, the authors have been forced to cut out exactly the detail which the new investigator most requires. Once he has learned to do one experiment involving spinal root stimulation and recording in a cat, the rest are not too difficult. But who will tell him how to minimize the bleeding which persists after even the most painstaking laminectomy? Not these authors, though they surely could. Their relentless inclusion of perhaps unnecessary experiments is a fault; some are now of historical interest only, like the measurement of chronaxie, and others are so difficult as to make them an absurd exercise for even postgraduate experiments, as, for example, the investigation of the rectification characteristics of the electrical synapses of crayfish giant axons. A book as good as this one is deserves criticism of this sort. Faced with the inclusion of less important experiments, one wonders at the omission of, for example, the use of the piezo-electric crystal for the controlled mechanical stimulation of receptors, or of reference to the exact control of stretch velocity in spindle investigation. And, as usual, the subject of the EEG is associated with a positive torrent of words, at quite a lower level of information content and interest to that of the rest of the book.

But certainly these authors are to be applauded for this largely rigorously presented work of instruction. "Only microelectrodes with a tip potential below $5 \mathrm{mV}$ are suitable for microelectrode work." In the face of such stern admonition, only the bravest will survive their course. And perhaps this is right, after all.

J. Diamond

\section{ECOLOGY OF AUSTRALIAN WATERS}

\section{Australian Inland Waters and their Fauna}

Eleven Studies. By A. H. Weatherley. Pp. xv+287+11 plates. (Canberra: Australian National University Press, 1967.) $\$ A 10.50$.

Much factual information is condensed in this book with the result that parts of the text are not very readable. It is, however, a work which will be of value to all who are interested in the ecology of inland waters. It emphasizes the unique and peculiar features of the Australian aquatic environment and shows that some established general principles do not apply to the inland waters of this continent.

There are eleven studies by ten contributors. The first three are concerned with the environmental setting and stress the main characteristics of the continent as they relate to inland waters. The major ionic composition of various water bodies in each state is given in a series of tables and in an extensive appendix there is a critical review of the sources of information on which each regional account is based. The last study in this section is an attempt at a biological classification of aquatic environments, illustrated by reference to Australian calanoid copepods (Centropagidae). There is a useful discussion of terminology and good reasons emerge for the introduction of the term "athalassic", referring to waters associated with land, the salts of which are derived by weathering of rocks and soils or indirectly from the sea, and in which a connexion with the sea either never existed in geologically Recent times or was permanently lost, with subsequent evaporation of the enclosed sea. The author's ideas on the possible evolutionary physiology of the Australian Centropagidae seem, however, to be without foundation.

The following five studies survey the fauna of Aus. tralian inland waters. An account of the present distribution of decapod Crustacea is followed by a study of the fresh water Mollusca and their probable evolutionary relationships. This is essentially a taxonomic study and 